\title{
ADAR1 enhances HTLV-1 and HTLV-2 replication through inhibition of PKR activity
}

\author{
Anne Cachat ${ }^{1,2,3,4,5}$, Sandrine Alais ${ }^{1,2,3,4,5+}$, Sébastien Alain Chevalier ${ }^{1,2,3,4,5 \dagger}{ }^{\text {, Chloé Journo }}{ }^{1,2,3,4,5}$, Floriane Fusil $\left.\right|^{3,4,5,6}$, \\ Hélène Dutartre ${ }^{1,2,3,4,5}$, Adrien Boniface ${ }^{1,2,3,4,5,7}$, Nga Ling Ko ${ }^{8}$, Antoine Gessain ${ }^{8}$, François-Loïc Cosset ${ }^{3,4,5,6}$, \\ Rodolphe Suspène ${ }^{9}$, Jean-Pierre Vartanian ${ }^{9}$ and Renaud Mahieux ${ }^{1,2,3,4,5^{*}}$
}

\begin{abstract}
Background: The role of innate immunity in general and of type I interferon (IFN-I) in particular in HTLV-1 pathogenesis is still a matter of debate. ADAR1-p150 is an Interferon Stimulated Gene (ISG) induced by IFN-I that can edit viral RNAs. We therefore investigated whether it could play the role of an anti-HTLV factor.

Results: We demonstrate here that ADAR1 is also expressed in the absence of IFN stimulation in activated primary T-lymphocytes that are the natural target of this virus and in HTLV-1 or HTLV-2 chronically infected T-cells. ADAR1 expression is also increased in primary lymphocytes obtained from HTLV-1 infected individuals. We show that ADAR1 enhances HTLV-1 and HTLV-2 infection in T-lymphocytes and that this proviral effect is independent from its editing activity. ADAR1 expression suppresses IFN-a inhibitory effect on HTLV-1 and HTLV-2 and acts through the repression of PKR phosphorylation.

Discussion: This study demonstrates that two interferon stimulated genes, i.e. PKR and ADAR1 have opposite effects on HTLV replication in vivo. The balanced expression of those proteins could determine the fate of the viral cycle in the course of infection.
\end{abstract}

Keywords: HTLV, Interferon, ADAR1, PKR

\section{Background}

Human T-cell leukemia virus type 1 (HTLV-1) was the first human oncoretrovirus to be discovered [1,2]. It infects 5 to 10 million people worldwide [3]. Among them, 3 to 5 percent have a lifetime risk to develop a lymphoproliferative disorder named adult T-cell leukemia (ATL) [4], or an inflammatory neurodegenerative disease named HTLV-1 associated myelopathy/tropical spastic paraparesis (HAM/ TSP) [5,6]. HTLV-2 infects 2 to 5 million people. Despite similarities with HTLV-1 in its genomic organization, HTLV-2 is only associated with rare cases of HAM/TSPlike diseases but does not promote leukemia or lymphoma $[7,8]$. The cause for such differences is a matter of investigation [9-18]. Nevertheless multiple reports already pointed out the key roles played both by Tax and HTLV-1 antisense-encoded protein in cell transformation [18-20].

\footnotetext{
* Correspondence: renaud.mahieux@ens-lyon.fr

${ }^{\dagger}$ Equal contributors

${ }^{1}$ Equipe Oncogenèse Rétrovirale, Lyon, Cedex 07, France

2Equipe labellisée "Ligue Nationale Contre le Cancer", Lyon, Cedex 07, France Full list of author information is available at the end of the article
}

Innate immunity plays a critical role in host response to a viral infection by triggering effector mechanisms that restrict infection [21]. Effectors of innate immunity such as restriction factors are present in cells before infection takes place and can act as immediate inhibitors of a given infectious agent. Double stranded RNA which is produced during replication of several viruses is a potent inducer of IFN-I which then acts as a signal to induce expression of antiviral effectors, among which Adenosine Deaminase Acting on RNA (ADAR), a cellular protein which edits RNA [22]. RNA editing which does not include capping, 3 ' processing, and splicing is defined as post-transcriptional events that modify RNA molecules. It is a natural process used by mammal cells to generate different variants of a given protein. ADAR enzymes are capable of editing double stranded RNA ([23] and for a recent review see [24]). There are three members of the mammalian ADAR family: ADAR1, ADAR2 and ADAR3. The formers convert adenosines into inosines, which are then translated into guanosines, 
while ADAR3 has no catalytic activity and seems mainly restricted to nervous system $[25,26]$.

There are two ADAR1 isoforms. ADAR1-p110 is constitutively expressed and found exclusively in the nucleus, while ADAR1-p150 is an Interferon Stimulated Gene (ISG) induced by IFN-I [27]. ADAR1-p150 is found in the nucleus and in the cytoplasm [28,29]. These two isoforms are generated from two distinct promoters and an alternative splicing of the first exon. ADAR1-p110 and ADAR1-p150 have a C-terminal catalytic deaminase domain, three dsRNA binding domains and one Z-DNA binding domain in ADAR1-p110 or two in ADAR1-p150. Both ADAR1 isoforms edit cellular and viral RNAs possessing a doublestranded structure $[30,31]$. Interestingly, several viruses produce dsRNA during their replication cycle [22].

As ADAR1-p150 expression can be induced by type I interferon, it was anticipated that it would be an effector of type I interferon antiviral effect on viral replication. Indeed, viral genome editing by ADAR1 was described for several viruses [30,32]. For example, ADAR1 edits hepatitis $\mathrm{C}$ viral genome and consequently reduces the level of $\mathrm{HCV}$ subgenomic RNA [33]. ADAR1 possesses a repressive activity against lymphocytic choriomeningitis virus (LCMV) [34], and bovine viral diarrhea virus (BVDV) [35]. Surprisingly however, ADAR1 plays a proviral role for other viruses such as vesicular stomatitis virus [36,37], Kaposi sarcomaassociated herpesvirus [38], Epstein-Barr virus [39], dengue virus [40] and Rift valley virus [31], while controversial results on hepatitis $D$, measles and influenza replication have been published [31,40-49]. ADAR1-p110 and ADAR1-p150 expression increases during the course of infection and promotes HIV-1 viral replication, thus playing a proviral role [50-53]. However, in this case, conflicting mechanisms have also been suggested: one study suggested that this effect requires ADAR1 editing activity, while another showed that ADAR1 proviral effect is independent from its catalytic site, but relies on the inhibition of the protein kinase R (PKR) function, which normally inhibits mRNA translation and induces apoptosis [50-52]. ADAR1-mediated PKR inhibition was also reported during measles virus or vesicular stomatitis virus infection $[36,37,49]$. Thus, depending on the viruses, ADARs can act either as antiviral or as proviral factors (for recent reviews, see [30,32]).

IFN- $\alpha$ is being used in combination to AZT to treat ATL patients, although the relationship between stimulation of innate immunity and impact on HTLV cycle are still not fully understood $[21,54,55]$. We recently demonstrated that PKR prevented HTLV-1 and -2 replication in cell culture following IFN-I treatment [11]. In another set of experiments using the exquisitely sensitive 3DI-PCR technique [56], we have also shown that HTLV-2 and simian T-cell leukemia virus type 3 (STLV-3) genomes can be edited by ADAR1 in cells transfected with HTLV-2 or STLV-3 molecular clones and an ADAR1-encoding plasmid [57].
However we could not find such mutations in ex vivo samples obtained from HTLV-2 infected individuals, thus demonstrating that ADAR1 editing of HTLV in vivo is a very rare phenomenon and is unlikely to play an antiviral role [57]. Though, consequences of ADAR1 expression on HTLV replication were not fully investigated in this report.

Here, we first demonstrate that ADAR1 is expressed in PHA/IL-2 activated primary T-lymphocytes in the absence of IFN-I stimulation, in HTLV-1 or HTLV-2 chronically infected $\mathrm{T}$-cells and in primary $\mathrm{CD} 4^{+}$cells obtained from HTLV-1 infected individuals. We show that ADAR1 enhances HTLV-1 and HTLV-2 infection in T-lymphocytes and that this proviral effect is independent from its editing activity. ADAR1 expression suppresses IFN- $\alpha$ inhibitory effect on HTLV-1 and HTLV-2 through repression of PKR phosphorylation. Together with our previous results, these studies demonstrate that two interferon stimulated genes, i.e. PKR and ADAR1 have opposite effects on HTLV replication in vivo. The balanced expression of those proteins could determine the fate of viral cycle in the course of infection.

\section{Results}

\section{ADAR1 is expressed in activated peripheral blood} lymphocytes and in HTLV-1 and HTLV-2 chronically infected $T$ cell lines

ADAR1 was previously shown to edit the genome of some RNA viruses and to act therefore as an antiviral factor $[31,34,44,45]$. Consequently we first wondered whether ADAR1 was expressed in primary uninfected T-lymphocytes that are the target of HTLV-1 and -2 retroviruses in vivo. Given that HTLV-1 infected T-lymphocytes display an activated phenotype [58], we first obtained Peripherical Blood Lymphocytes (PBLs) from two healthy blood donors and activated them with PHA and IL-2. An aliquot of the same cells was also left quiescent. As expected, ADAR-p110 form was constitutively expressed, while ADAR1-p150 expression was induced following T-cell activation (Figure 1A). As a control, primary B-cells were also purified from normal PBLs and left quiescent or activated with Pansorbin for 24 and 48 hours. As observed for T-cells, B-cell activation led to a strong increase in ADAR-1 expression (Figure 1B), thus suggesting that increase in ADAR1 expression is linked to cell activation.

Then, we compared the expression of both ADAR1 isoforms in non-infected Jurkat T-lymphocytes as well as in HTLV-1 (C91-PL and MT2) or HTLV-2 (C19 and MO) infected T-lymphocytes (Figure 1C). While ADAR1-p110 was expressed in all transformed cells including Jurkat, ADAR1-p150 was specifically up-regulated in HTLV-1 and HTLV-2 chronically infected cells.

Finally, CD4 ${ }^{+}$T-cells were isolated from the blood of two HTLV-1 infected individuals and stimulated with PHA and IL-2 for 3 days then grown only with IL-2. For 


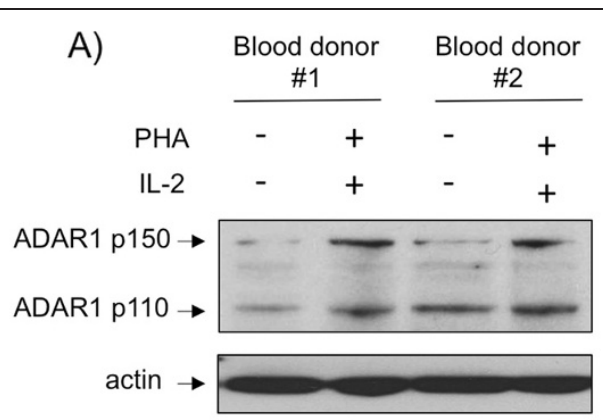

B)
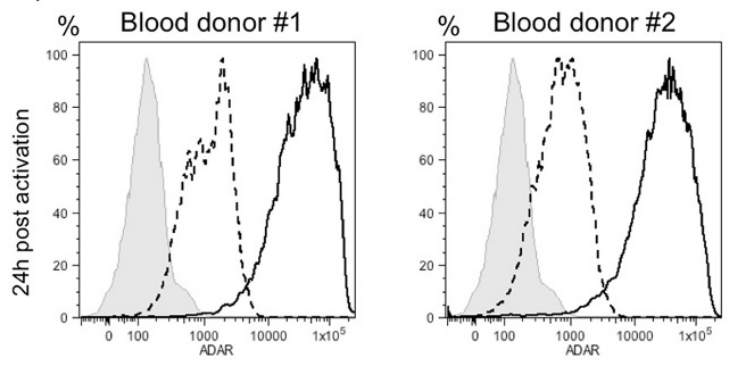
Control
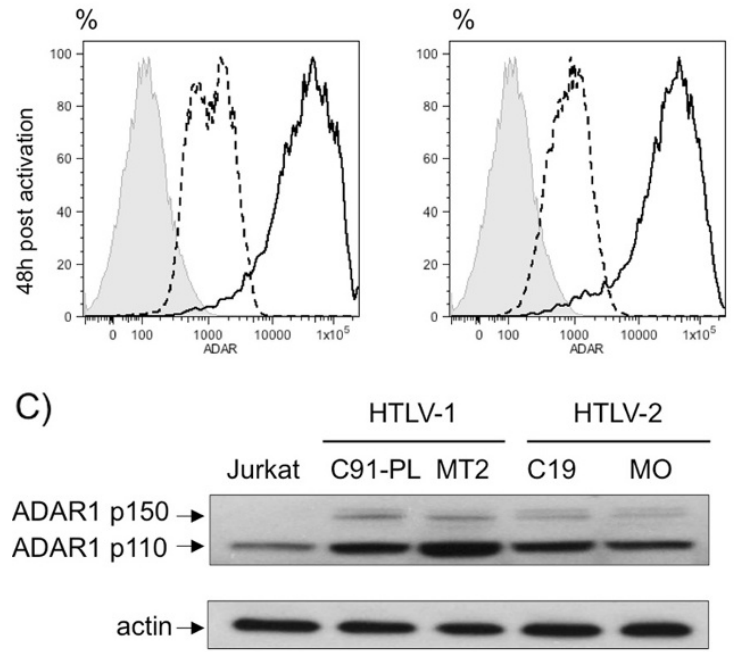

D)

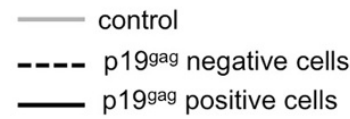

HTLV-1 infected individuals $\quad$ \#1

\#2
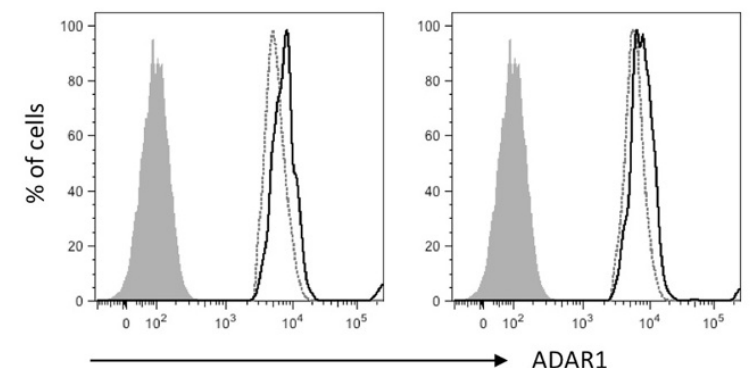

Figure 1 (See legend on next page.) 
(See figure on previous page.)

Figure 1 ADAR1 is expressed in activated lymphocytes as well as in HTLV-1 and HTLV-2 chronically infected T-cell lines and primary

T-lymphocytes from HTLV-1 infected individuals. (A): Whole cell extracts $(60 \mu \mathrm{g})$ obtained from PBLs activated or not with PHA/L-2 for 72 hours.

(B): B-cells were purified from the PBMCs of two blood donors and left unactivated (dot line) or treated with Pansorbin (solid line). ADAR1 expression was measured $24 \mathrm{~h}$ and $48 \mathrm{~h}$ later (FACS Canto II, BD Biosciences). Isotype control is represented with a grey histogram (C): Uninfected- (Jurkat),

HTLV-1-infected (C91-PL, MT2) and HTLV-2-infected (C19, MO) cells were analyzed by western-blot analyses using anti-ADAR1 or anti-actin antibody. (D): CD4 ${ }^{+}$T-cells from two HTLV-1 positive individuals were sorted, stimulated with PHA and cultured in the presence of IL-2. Cells were stained with anti ADAR1 and anti HTLV p19 $9^{\text {gag }}$ antibodies followed by APC anti-rabbit and FITC anti-mouse antibodies. CD4 ${ }^{+}$cells from p19 $9^{\text {gag }}$ negative population (dot line) or from p19gag positive population (solid line) were analyzed for ADAR1 expression. (B, D): Cells were analyzed on a FACS-Canto II

(BDSciences) collecting 100000 events. Results analyzed using FlowJo software.

each sample, ADAR-1 expression was then measured by flow cytometry in the fraction of $\mathrm{CD} 4^{+}$cells that express HTLV-1 (p19 ${ }^{\mathrm{gag}}$ ) antigen and compared to the $19^{\text {gag }}$ negative population. Interestingly, HTLV-1 productively infected cells expressed higher levels of ADAR1 than cells that were also stimulated but did not express HTLV-1 antigens (Figure 1D).

Altogether, these results show that both isoforms of ADAR1 are expressed in the absence of IFN-I stimulation in activated T-cells that are susceptible to HTLV-1 and HTLV-2 infection. They also demonstrate that HTLV-1 and HTLV-2 chronically infected cells express the inducible ADAR1 isoform and suggest that HTLV-1 expression is correlated with an increased ADAR1 expression in primary $\mathrm{CD} 4^{+} \mathrm{T}$-cells.

\section{ADAR1 has a proviral effect on de novo HTLV-1 and HTLV-2 infection in T- lymphocytes}

Then, we investigated the effect of ADAR1 expression on de novo infection of T-cells with HTLV-1 and HTLV2 using a previously described protocol (Figure 2A) [11].

HTLV-1/-2 infection occurs mainly through cell-cell contact. Target Jurkat (Figure 2B, C) or primary PBLs (Figure 2D, E) were therefore co-transfected with a plasmid encoding ADAR1 and a plasmid encoding the luciferase indicator gene under the control of the HTLV-1 or HTLV-2 LTR promoters. Twenty-four hours later, target cells were co-cocultured with gamma-irradiated C91-PL (HTLV-1), C19 (HTLV-2) donor cells or non-infected Jurkat cells. The viral non-structural Tax protein is necessary for activating transcription from the LTR. Consequently, luciferase activity monitors viral infection i.e. viral entry, reverse transcription, integration and viral expression in target cells (Figure 2A).

ADAR1 expression in target Jurkat cells significantly enhanced luciferase activity after co-culture with HTLV-1 or HTLV-2 infected irradiated T-cells (Figure 2B compare lane 3 vs. 4 , and Figure $2 \mathrm{C}$ lane 3 vs. 4). These results suggest that ADAR1 increases target cells susceptibility to HTLV-1 and HTLV-2 infection. As a control, ADAR1 did not affect the level of luciferase activity in target Jurkat target cells co-cultured with non-infected T-cells (Figure 2B and $C$ lanes 1-2).

Similar experiments were then performed using primary PBLs obtained from healthy blood donors as target cells, instead of Jurkat cells. As in Jurkat, ADAR1 expression in PBLs was associated with an increased luciferase activity (Figures 2D and E compare lane 2 vs. 4). To control that luciferase activity was linked to viral infection and not a passive Tax transfer from donor to target cells, we performed a series of control experiments where PBLs were treated or not with AZT, an inhibitor of reverse transcription. As expected, AZT treatment strongly reduced luciferase activity thus demonstrating that de novo Tax synthesis is required in the target cells (Figure 2D and E, lanes 2 vs.3).

These results demonstrate that ADAR1 has a proviral effect on HTLV-1 and HTLV-2 de novo infection both in $\mathrm{T}$-cell lines and in primary $\mathrm{T}$ - lymphocytes.

\section{ADAR1 increases HTLV-1 and HTLV-2 protein expression}

To decipher how ADAR1 affects HTLV-1/2 replication, Jurkat (Figure 3A-B) or primary T-lymphocytes (Figure 3CD) were transfected with molecular clones which contain full length proviruses together with HTLV-1 or HTLV-2LTR-luciferase reporter, in the presence or absence of ADAR1. This system allows us to bypass the entryintegration viral steps cells. In both settings, ADAR1 expression was associated with an increased luciferase activity, thus indicating up-regulation of Tax1 and Tax2 protein expression (Figure 3A-D compare lane 2 and 3). Of note, in the presence of ADAR1 plasmid, a higher increase in luciferase activity was observed when Jurkat cells were transfected with the HTLV-1 molecular clone than with the HTLV-2 clone. This effect was not observed in primary Tcells.

293T-LTR-GFP cells were then transfected with HTLV-1 or HTLV-2 molecular clones. These cells stably harbor a GFP reporter gene whose expression parallels activation of LTR-driven transcription. Consistent with co-culture experiments, ADAR1 expression increased the number of GFP positive cells, thus demonstrating an increased Tax-mediated LTR transcription (Figure 3E compare minus and plus ADAR1). ADAR1 expression was also associated with an increased number of syncitia, indicative of a higher HTLV envelope protein expression (Figure 3E, compare minus and plus ADAR1). In addition, most GFP positive cells were also strongly positive for ADAR (Figure 3F). Western-blot analyses, 
A)

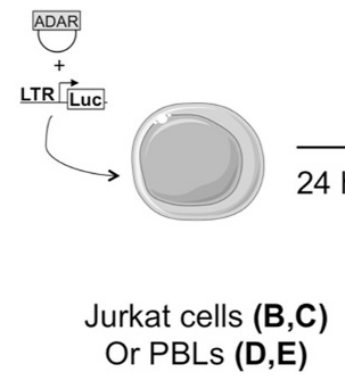

B) Target cells: Jurkat

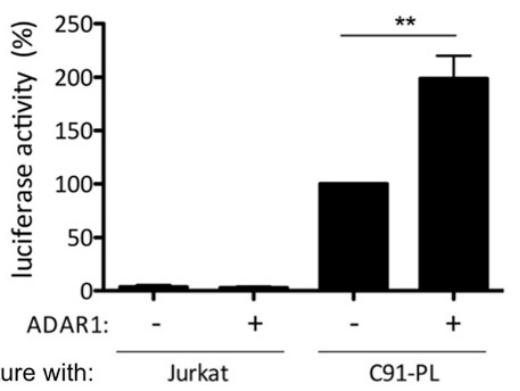

D) Target cells: PBLs

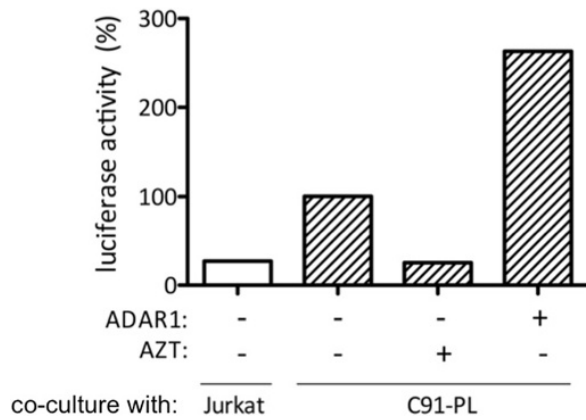

Target

cell
LTR LuC,

LTR LUC.

ADAR

;

24 hours

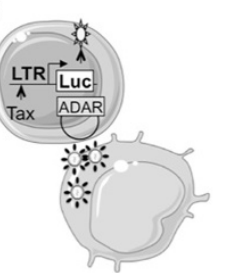

Coculture with

HTLV infected cells

Luciferase assay

C) Target cells: Jurkat

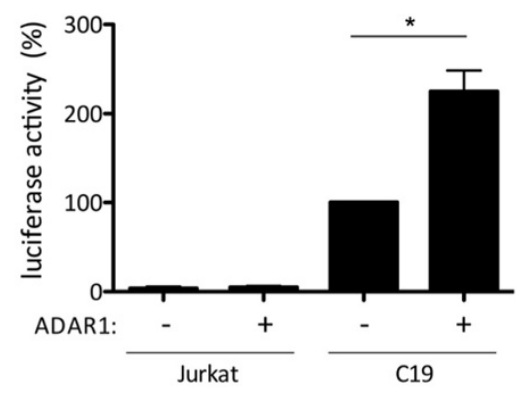

E) Target cells: PBLs

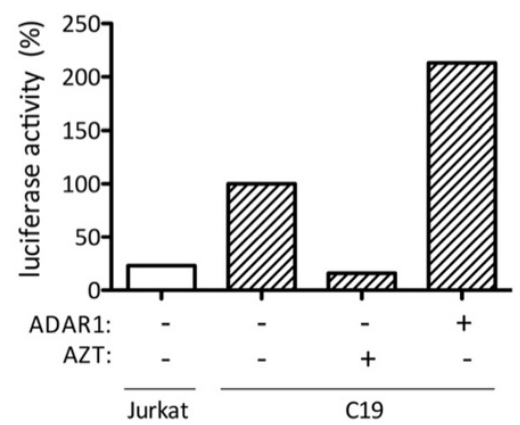

Figure 2 ADAR1 has a proviral effect on de novo HTLV-1 and HTLV-2 infection in T-lymphocytes. (A): Jurkat or PBLs were transfected either with $2.5 \mu \mathrm{g}$ of an ADAR1 or of a backbone vector, together with $2.5 \mu \mathrm{g}$ of a plasmid encoding the luciferase gene under the control of the HTLV-1-LTR or HTLV-2-LTR. Twenty-four hours later, Jurkat (B, C) or PBLs (D, E) were co-cultured with (B, D) irradiated C91-PL (HTLV-1), (C, E) C19 (HTLV-2) or (B, C, D, E) Jurkat (non-infected) cells for 24 hours. Luciferase activity was measured, and results normalized by protein concentration as determined by the Bradford method and calculated as fold change compared to infected cells transfected with the control plasmid arbitrarily set to 100\%. (D, E): PBLs were treated with AZT $(50 \mu \mathrm{M})$ before the co-culture with C91-PL or C19 irradiated cells. (B, C): Data are the mean \pm standard deviation (SD) from 3 independent experiments. Asterisks indicate statistically significant differences between treated and untreated cells (paired Student $t$ test, ${ }^{*} p<0.05$; $\left.{ }^{* *} p<0.01\right)$. (D, E): Data are representative of two different experiments obtained with two different blood donors.

performed on 293T-LTR-GFP cells transfected with a constant amount of HTLV-1 (Figure 3G) or HTLV-2 molecular clone (Figure $3 \mathrm{H}$ ) and increasing amounts of ADAR1 confirmed those observations. Indeed, both Tax1, Tax2 and $\mathrm{p} 24^{\text {gag }}$ protein expression levels increased in a dose dependent manner (Figure 3G-H). As a control, actin levels remain constant under the same conditions. The amount of $\mathrm{p} 19^{\text {gag }}$ in the culture supernatant, which is assumed to reflect the quantity of viral particles, was also measured in the same experimental conditions. Consistent with western-blot results, p19 gag in the supernatant also increased in a dose-dependent manner (Figure 3I, J).

Thus, these results demonstrate that ADAR1 increases viral expression and viral production in all cell lines tested.

\section{ADAR1 expression does not impair the production of infectious viral particles}

Given that ADAR1 possesses an editing activity, we then wondered whether viral particles produced in the presence of ADAR1 were infectious or not. 293T cells were 


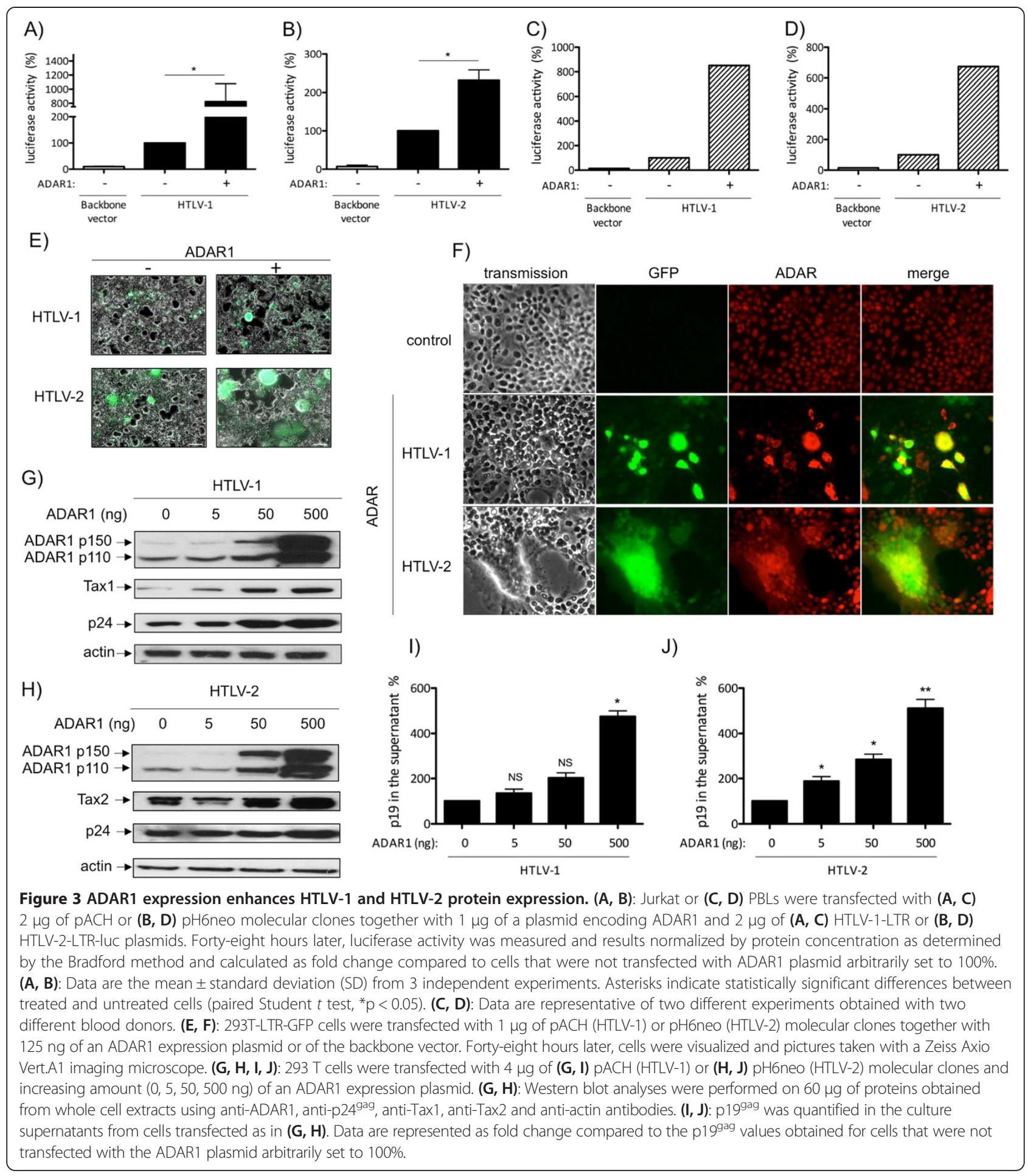

transfected with HTLV-1 or HTLV-2 molecular clones and increasing amount of ADAR1 plasmid. Forty-eight hours after transfection culture medium was removed, cells were extensively washed before being co-cultured with Jurkat-LTR-luciferase cells (Figure 4A). We observed a dose-dependent increase in luciferase activity, suggesting that viral particles that are made in the presence of ADAR1 are still capable of replication in their target cells (Figure 4B, C). To control that luciferase activity measured in Jurkat target cells was not due to a passive Tax transfer from the transfected cell to the target cell, 293-T cells were transfected with Tax1 or Tax2 plasmids and co-cultured with Jurkat-LTRluciferase cells. Luciferase activity was measured and 
A)

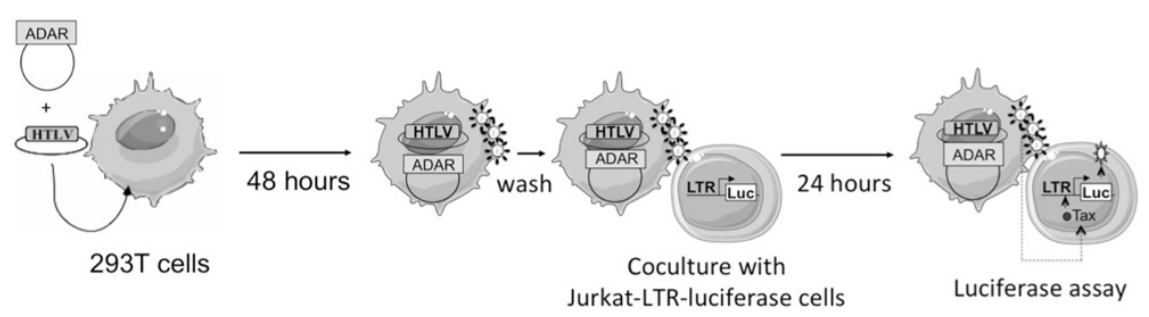

B)

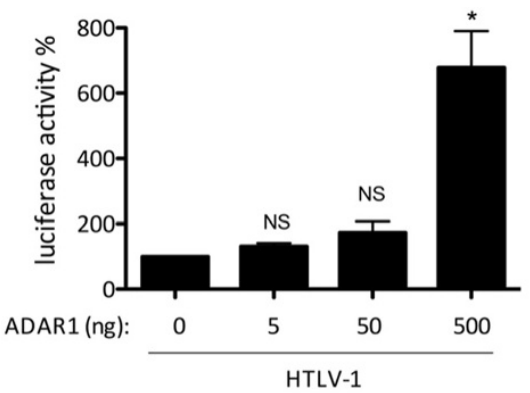

D)

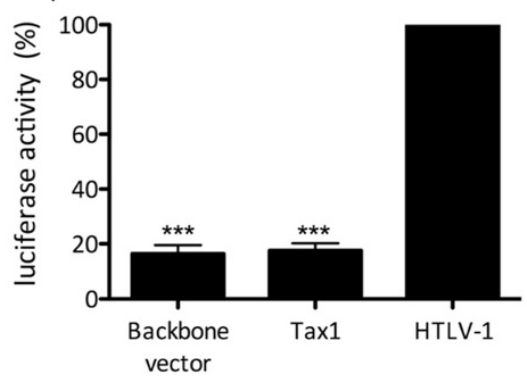

C)

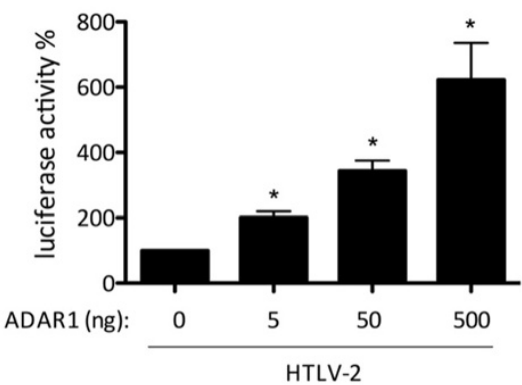

E)

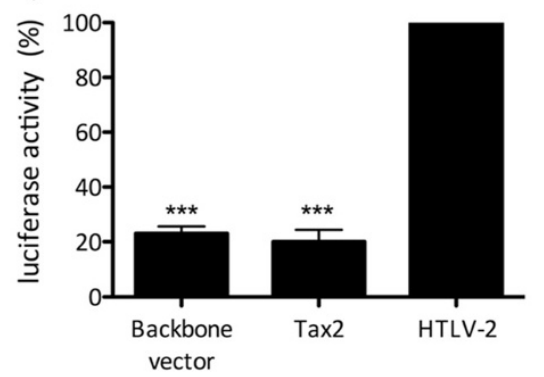

Figure 4 ADAR1 expression does not affect viral infectivity. (A): 293-T cells were transfected with $4 \mu \mathrm{g}$ of (B) pACH or (C) pH6neo molecular clones and increasing amount $(0,5,50,500 \mathrm{ng})$ of an ADAR1 expression plasmid or $8 \mu \mathrm{g}$ of (D) pSG5M-Tax1, (E) pSG5M-Tax2 or backbone vector. Forty-eight hours later, cells were washed and co-cultured with Jurkat-LTR-luc cells for 24 hours (ratio 1:3). Luciferase activity results were normalized to protein concentration as determined by the Bradford method and calculated as fold change compared to cells non transfected with ADAR1 plasmid arbitrarily set to $100 \%$. Data are the mean \pm standard deviation (SD) from 3 independent experiments. Asterisks indicate statistically significant differences between treated and untreated cells (paired Student $t$ test, ${ }^{*} p<0.05 ;{ }^{* * *} p<0.001$; NS: non significant).

was similar to that of $293 \mathrm{~T}$ cells transfected with a backbone vector (Figure 4D, E).

Altogether, these results demonstrate that ADAR1 has a proviral effect, enhances HTLV-1/-2 expression and release of infectious particles.

\section{ADAR1 proviral effect is independent from its editing activity}

We next wondered whether ADAR1 proviral effect was dependent or not of its editing activity. Using a previously described ADAR1 RNA editing reporter system [40], we first verified that the plasmid encoding ADAR1 with a mutation in its catalytic site was deficient for its editing activity. The unedited reporter plasmid contains a stop codon that is converted into Trp codon when A to I editing by ADAR1 occurs. As a consequence, editing by ADAR1 is correlated with Firefly luciferase expression. As expected, transfection of wild-type ADAR1 induced an increased luciferase activity (Additional file 1: Figure S1 left graph), while ADAR1 mutant did not lead to any increase in luciferase expression (Additional file 1: Figure S1 right graph).

Then, 293-T cells were transfected with HTLV-1 or HTLV-2 molecular clones, in the presence of plasmids encoding either wild-type ADAR1 or the editing-deficient ADAR1 mutant. p24 $4^{\text {gag }}$ western-blot (Figure 5A, B) or p19 ${ }^{\text {gag }}$ ELISA (Figure $5 \mathrm{C}, \mathrm{D}$ ) revealed that expression of both wild-type or mutant ADAR1 led to a similar increase in viral protein expression and virus release.

Next, to confirm that editing has no effect on HTLV transcription, we used Jurkat cells transfected with the HTLV-LTR-luciferase reporter plasmids and co-transfected with HTLV-1 or HTLV-2 molecular clone, together with wild-type or editing-deficient ADAR1 constructs (Figure 5E, F). A similar increase in luciferase activity was observed with 


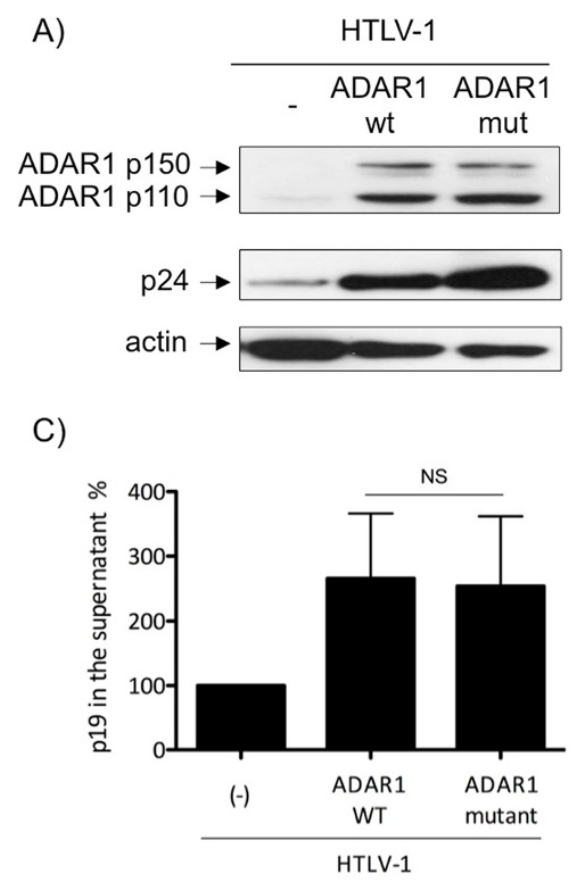

E)

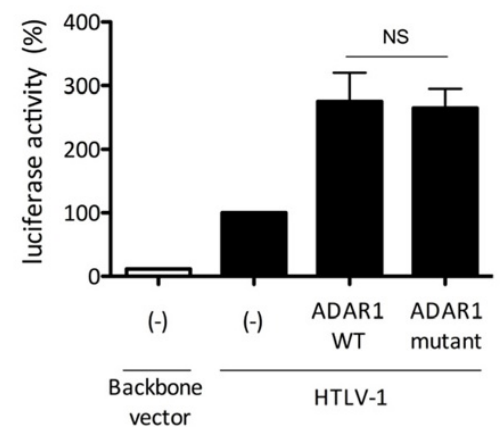

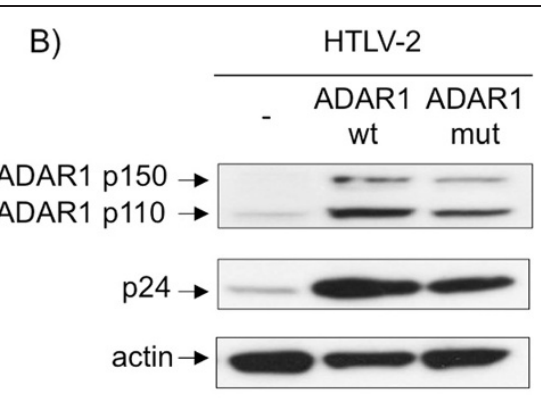

D)

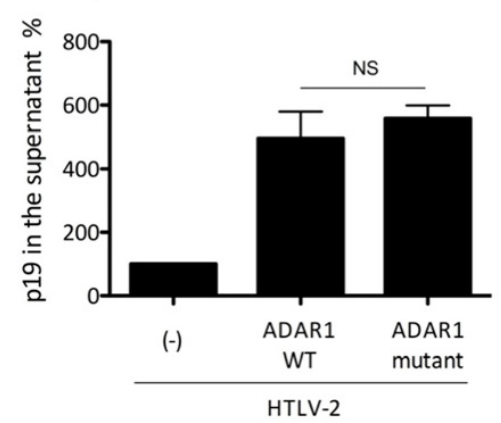

F)

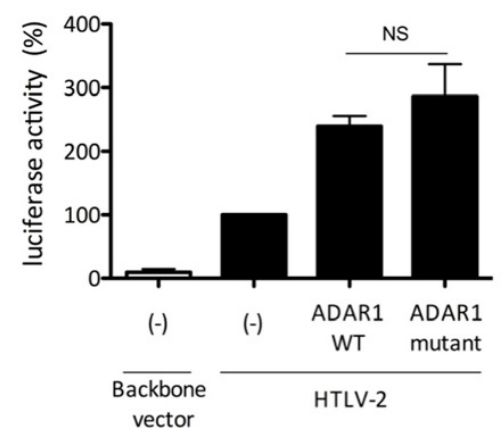

Figure 5 ADAR1 enhances HTLV-1 and HTLV-2 replication independently from its editing activity. 293-T cells were transfected with (A, C) $4 \mu \mathrm{g}$ of pACH or (B, D) pH6neo molecular clones together with $500 \mathrm{ng}$ of a plasmid coding for ADAR1 wild-type or for an editing-deficient ADAR1 protein (ADAR1 mutant). (A, B): Western blot analyses were performed on $60 \mu \mathrm{g}$ of proteins obtained from whole cell extracts using anti-p24 ${ }^{\text {gag }}$, anti-ADAR1 and anti-actin antibodies. (C, D): p19gag was quantified in supernatant obtained from cells transfected as in (A, B). Data are represented as fold change compared to the p1 $9^{\text {gag }}$ values obtained for cells that were not transfected with the ADAR1 plasmid arbitrarily set to $100 \%$. (E, F): Jurkat cells were transfected with $2 \mu \mathrm{g}$ of (E) pACH or (F) pH6neo molecular clones, together with $1 \mu \mathrm{g}$ of a plasmid encoding either ADAR1 wild-type or ADAR1 mutant and $2 \mu \mathrm{g}$ of (E) HTLV-1-LTR or (F) HTLV-2-LTR-luc plasmid. Forty-eight hours later, luciferase activity was measured and results normalized to protein concentration as determined by the Bradford method and calculated as fold change compared to cells non transfected with ADAR1 plasmid arbitrarily set to 100\%. (C-F): Data are the mean \pm standard deviation (SD) from 3 independent experiments. Asterisks indicate statistically significant differences between treated and untreated cells (paired Student $t$ test; NS: non significant).

wild-type or mutant ADAR1. We also determined whether viral particles produced in the presence of both wild-type or mutant ADAR1 plasmids were infectious by performing a coculture assay as described in Figure 2A. ADAR1 mutant expression increased the release of infectious viral particles similarly to ADAR1 wild-type both in HTLV-1 and HTLV-2 settings (Additional file 2: Figure S2).

Altogether, these results confirm that ADAR1 proviral effect on HTLV-1 and HTLV-2 replication is independent from its editing activity.

\section{ADAR1 proviral effect is mediated through inhibition of PKR activation}

PKR is an ISG that has been shown to be involved, once activated by phosphorylation, in a signaling pathway leading to inhibition of mRNA translation. It was previously established that ADAR1 antagonizes PKR activation [37,49]. This effect requires double-strand RNA binding of ADAR [37]. We therefore wondered whether ADAR1 proviral effect on HTLV-1 and HTLV-2 could be mediated through PKR inhibition. To test this hypothesis, PKR western-blots 
were performed on protein extracts obtained from 293-T cells transfected with HTLV-1 and HTLV-2 molecular clones together with increasing amount of ADAR1 (Figure 6A, B). Consistent with results presented above, the amount of p24 $4^{\mathrm{gag}}$ and Tax viral proteins increased in an ADAR1 dose dependent manner, while the level of PKR remained constant (Figure 6A, B compare lane 1 vs 2-4). Interestingly, the level of phospho-PKR (i.e. the active form of PKR) was inversely correlated with that of ADAR1 (Figure 6A, B, compare lane 1 and 4).

To demonstrate that ADAR1 proviral effect was linked to the inhibition of PKR activation, cells were transfected either with PKR siRNA or with control siRNA before being transfected with HTLV-1/2 molecular clones and ADAR1 plasmid (Figure 6C, D). As previously described [11], PKR extinction results in an increased p24 expression. However, despite ADAR1 ectopic expression, the level of $\mathrm{p}^{\mathrm{gag}}{ }^{\mathrm{g}}$ remained constant, in cells transfected with PKR siRNA, while it increased when control siRNA were transfected.
These results demonstrate that ADAR1 effect on HTLV-1 and HTLV-2 is linked to the inhibition of PKR phosphorylation. A previous study demonstrated that HIV-1 Tat interacts with PKR and inhibited PKR auto-phosphorylation thus providing a possible mechanism of IFN suppression [59]. We therefore tested whether Tax could also bind and inhibit PKR. However no interaction between Tax and PKR was observed (data not shown).

\section{ADAR1 expression reverses IFN- $a$ inhibitory effect on HTLV-1 and HTLV-2}

We have recently shown that IFN- $\alpha$ restricts HTLV-1 and HTLV-2 de novo infection by inhibiting viral protein synthesis through PKR activation [11]. Since ADAR1 inhibits PKR activation and enhances viral protein translation, we finally wondered whether IFN- $\alpha$ still had an antiviral effect in the presence of ADAR1 ectopic expression.

293-T cells were transfected with HTLV-1 (Figure 7A) or HTLV-2 molecular clones (Figure 7B), with or without an

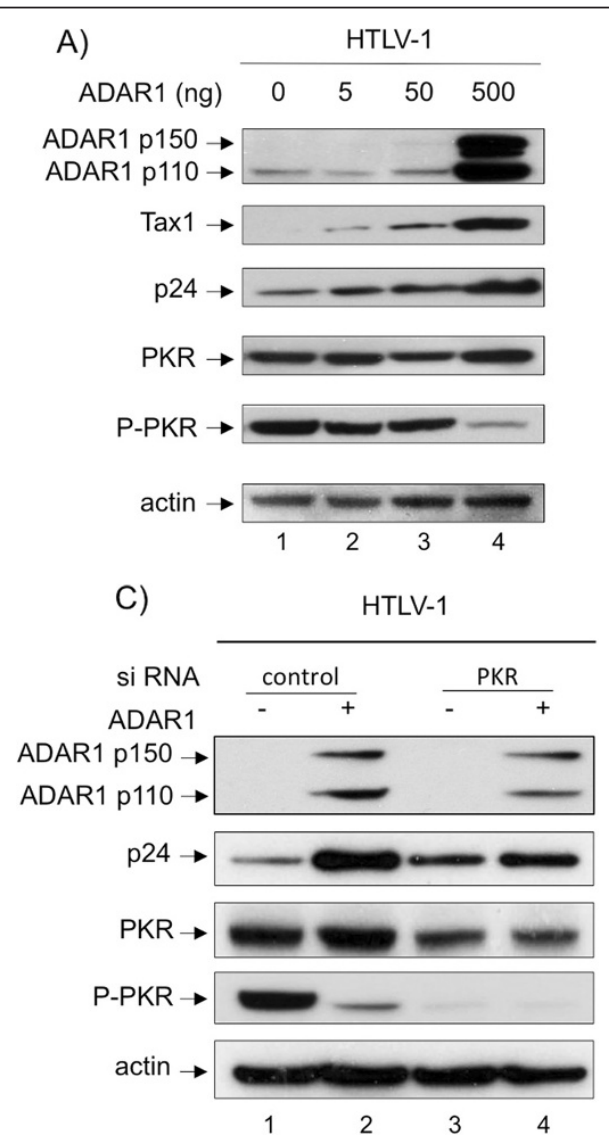

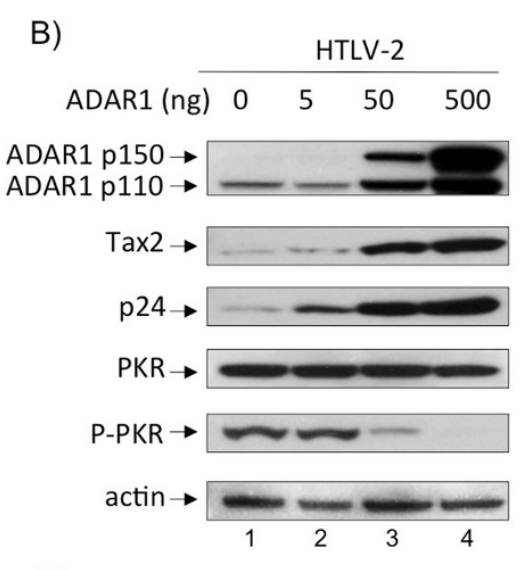

D)

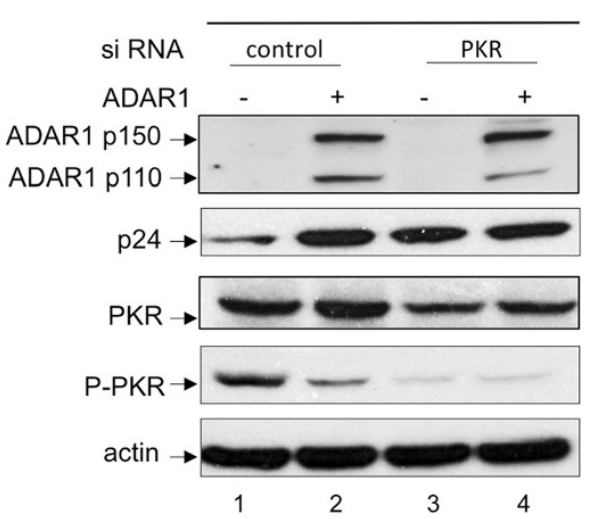

Figure 6 ADAR1 proviral effect is mediated through inhibition of PKR activation. 293-T cells were transfected with $4 \mu \mathrm{g}$ of (A) pACH or (B) pH6neo molecular clones and increasing amount $(0,5,50,500 \mathrm{ng})$ of ADAR1 plasmid. Western blot analyses were performed on $60 \mu \mathrm{g}$ of proteins obtained from whole cell extracts using anti-ADAR1, anti-p249ag, anti-Tax1, anti-Tax2, anti-PKR, anti-phospho-PKR and anti-actin antibodies. (C, D): 293-T cells were transfected with siRNA directed against PKR (20nM) or with control siRNA. Twelve hours later cells were transfected with 20nM of the same siRNA together with $1.2 \mu \mathrm{g}$ of (C) pACH, (D) pH6neo and $125 \mathrm{ng}$ of an ADAR1 expression plasmid. Western blot analyses were performed on $60 \mu \mathrm{g}$ of proteins obtained from whole cell extracts using anti-ADAR1, anti-p24 ${ }^{\text {gag }}$, anti-PKR, anti-phospho-PKR and anti-actin antibodies. 


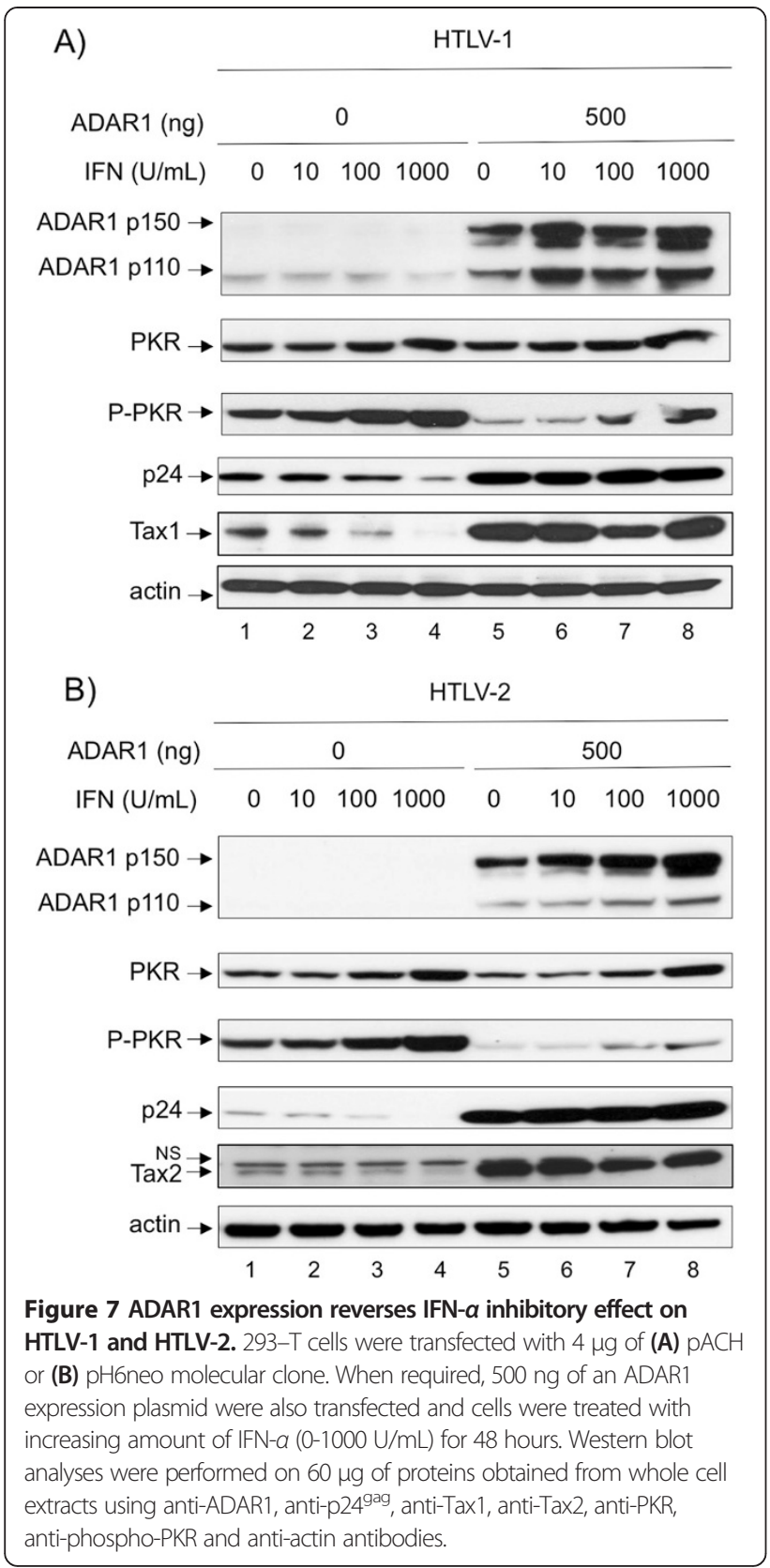

ADAR1 expression plasmid, before being treated with increasing amounts of IFN- $\alpha$. In the absence of ADAR1 over-expression and consistent with our previous data [11], IFN- $\alpha$ treatment led to a decreased $\mathrm{p} 24^{\mathrm{gag}}$ as well as Tax1 or Tax 2 protein expression (Figure $7 \mathrm{~A}$ and $\mathrm{B}$, compare lane 1 and 4). This effect was correlated with an increase in PKR and phospho-PKR levels. In the presence of ectopic ADAR1, IFN- $\alpha$ treatment still lead to increased PKR levels, but the levels of phospho-PKR remained low and were not associated with a decreased $\mathrm{p} 24^{\text {gag }}$ or Tax expression (Figure 7A and B, compare lane 5 and 6-8).
These results show that IFN- $\alpha$ cannot activate PKR in the presence of elevated levels of ADAR1, thus ADAR1 expression prevents PKR from having its antiviral role.

\section{Discussion}

ADAR1 is responsible for A-to-G (I) editing of cellular and viral genes [30,31]. Editing can be site-selective in the case of Hepatitis virus D [41,42] or of L-glutamate receptor [60]. It can also be non-selective in the case of Hepatitis $\mathrm{C}$, influenza, measles and Rift valley viruses [31,33,44]. As ADAR1 expression is induced by IFN-I, it was originally anticipated that IFN-I antiviral effects occur at least partly through an ADAR1 dependent editing of viral genomes. Indeed, Taylor et al. demonstrated that IFN- $\alpha$ treatment induces A-to-I editing in HCV replicon cells, while HCV editing is reduced when ADAR1 enzymatic activity is inhibited [33].

We previously demonstrated that co-transfecting ADAR1 together with HTLV-2 or STLV-3 molecular clones in 293-T cells led to A-to-G editing although the frequency of such editing could not be quantified [57]. A similar observation was made for measles and influenza viruses [44]. However, such hyper-edited sequences were only detected using the exquisitely sensitive 3DI-PCR technique [31], and replication of those viruses was not tested. In addition, editing was not observed in a series of samples obtained from 20 HTLV-2 infected individuals, although ADAR1 mRNA was present in those samples. This suggested that A-to-G (I) editing is an extremely rare phenomenon in vivo, at least in HTLV-2 infected cells [57].

As HTLV-1 mostly infects CD4 $4^{+}$T-lymphocytes and HTLV-2 infects $\mathrm{CD} 8^{+}$T-lymphocytes [16], we measured here ADAR1 p110 and p150 expression in peripheral blood lymphocytes that were left quiescent or PHA/IL-2 activated. Consistent with a previous study [61], both ADAR1 isoforms were present in activated lymphocytes. Thus, ADAR1 is expressed in cells that are targets of HTLV-1 and HTLV-2. Consistent with data obtained on HTLV-2 ex vivo samples [57], we have also shown that ADAR1 expression is higher in HTLV-1 and HTLV-2 chronically infected lymphocytes compared to noninfected T-cells and in primary $\mathrm{CD} 4^{+}$T-cells obtained from HTLV-1 infected individuals, thus suggesting that ADAR1 is expressed in response to HTLV infection. Interestingly, Clerzius et al have also shown that ADAR1-p110 and ADAR1-p150 expression is increased when Jurkat cells are infected with HIV-1 [50]. It could be of interest to determine in the future which factor induces ADAR1 expression in HTLV-1/-2 infected cells.

ADAR1 proviral effect was previously observed for different viruses [36,37,40,49-52]. This effect is mediated through (1) viral RNA editing, (2) the inhibition of PKR through the formation of an ADAR1/PKR complex [37,50] or (3) an increase in ADAR1 catalytic activity. We have shown here that ADAR1 effect on HTLV-1/-2 replication is independent 
from ADAR1 editing activity and is rather linked to the inactivation of PKR function. It could also be of interest to determine whether ADAR1 effect is also linked to the formation of a complex between those two cellular proteins. Of note, our results do not exclude the fact that ADAR1 editing on HTLV-1/2 genomes might also occur, but at a very low frequency thus having no deleterious effect on viral cycle.

Shoggins et al have recently developed an assay to study the effect of hundreds of ISG products on different viruses that belong to Flaviviridae (YFV, WNV), Togaviridae (CHIKV, VEEV) or Retroviridae (HIV-1) [53]. This led to the identification of ISGs that are strong repressors, modest inhibitors, but also that are activators of viral cycle. In this study, ADAR was identified as an enhancer of replication for all viruses tested. Interestingly, the authors also tested the combination of one inhibitory and one enhancing ISG on viral cycle, and showed that, in most cases, viral replication was more influenced by the inhibitory than by the enhancing ISG [53]. Thus, this study highlighted that IFN-I does not necessarily promote an antiviral state and that a subtle balance between repressor and activator ISGs regulate the fate of viral infections.

We have previously shown that IFN- $\alpha$ inhibits HTLV-1 and HTLV-2 de novo infection through PKR activation [11]. We demonstrated here that another ISG, ADAR1 p150 is expressed in activated T-cells and plays a proviral role on HTLV-1 and HTLV-2 replication. We can therefore elaborate a working hypothesis that, during primary infection and in the absence of IFN-I, HTLV-1/-2 will infect cells that express ADAR1 p150 but not PKR. In this case, ADAR1 will play a proviral role. Infection could then lead to IFN-I production that could in turn activate both PKR and ADAR-1 p150 in surrounding cells. In this case, according to Schoggins et al., PKR could play an antiviral role [53]. Given that IFN-I is used to treat chronic ATL patients [62], it would therefore be interesting to measure quantitatively the expression of both PKR and ADAR in ATL cells if those samples were available.

\section{Conclusions}

In conclusion, our results demonstrate that IFN-I promotes the expression of two ISG that have antagonist roles on HTLV replication.

\section{Methods}

\section{Cell culture and flow cytometry}

293T and 293T-LTR-GFP cells were maintained in Dulbecco's modified Eagle's medium (DMEM) supplemented with $10 \%$ fetal bovine serum (Gibco, Life technologies) and $100 \mu \mathrm{g} / \mathrm{mL}$ penicillin-streptomycin (Gibco, Life technologies). Jurkat, Jurkat-LTR-luc, HTLV-1- (C91/PL, MT2) and HTLV-2-infected T-cell lines (C19, MO), were maintained in RPMI 1640 medium supplemented with 10\% fetal bovine serum (Gibco, Life technologies) and $100 \mu \mathrm{g} /$ $\mathrm{mL}$ penicillin-streptomycin (Gibco, Life technologies). Peripheral blood lymphocytes (PBL) were purified from blood samples obtained from healthy donors (Etablissement Français du Sang, Lyon) or from HTLV-1 infected individuals. HTLV-1 infected blood samples were obtained in the context of a Biomedical Research Program approved by the "comité de protection des personnes", Ile de France III, Paris (2007-A01103-50, number 2494) with informed consent of all individuals. Cells maintained in RPMI 1640 medium supplemented with $10 \%$ fetal bovine serum (Gibco, Life technologies) and $100 \mu \mathrm{g} / \mathrm{mL}$ penicillinstreptomycin (Gibco, Life technologies). PBL were either left quiescent or stimulated with phytohemagglutinin (PHA, $1 \mu \mathrm{g} / \mathrm{mL}$, SIGMA) and interleukin-2 (IL-2 at $150 \mathrm{U} /$ $\mathrm{mL}$ ). When required, IFNo-2a (Tebu-Bio) was added for 3 days to the cells. 293T-LTR-GFP and Jurkat-LTR-luc are stably transfected with a plasmid encoding GFP (green florescent protein) or luciferase under the control of HTLV-1 long terminal repeat (LTR), respectively [63,64]. All cell lines were grown at $37^{\circ} \mathrm{C}$ in $5 \% \mathrm{CO}_{2}$.

\section{B-cells analyses}

CD $19^{+} \mathrm{B}$ cells were purified by depletion/negative selection using a B-cell isolation kit (Miltenyi Biotech). Purity of isolated B-cells was monitored using anti-hCD19 VioBlue (Miltenyi Biotech) and was analyzed by fluorescence-activated cell sorting (FACS CantoII; BD Biosciences).

B-lymphocytes were cultured in RPMI 1640 medium (Gibco BRL Invitrogen) supplemented with 10\% FCS and $1 \%$ penicillin/streptomycin with $50 \mathrm{ng} / \mathrm{ml} \mathrm{IL2} \mathrm{(Mil-}$ tenyi Biotech). They were either treated with Pansorbin $200 \mathrm{ng} / \mathrm{ml}$ (Millipore Calbiochem) (activated condition) or left untreated (non activated condition). $24 \mathrm{~h}$ and $48 \mathrm{~h}$ later cells were labeled with hCD19-PE, hCD3-PE and hCD69-PEvio770 (Miltenyi Biotech). ADAR antibodies (Abcam) were used after permeabilization/ fixation using the Cytofix/Cytoperm kit (BD).

\section{T-cells analyses}

$\mathrm{CD}^{+}{ }^{+}$T-cells obtained from healthy donors or HTLV-1 infected individuals were purified by depletion/negative selection using T-cell isolation kit (Miltenyi Biotech). Purity of $\mathrm{CD}^{+}$T-cells was monitored using antihCD4APC antibodies (Miltenyi Biotech) and was analyzed by fluorescence-activated cell sorting (FACS CantoII; BD Biosciences). CD4 ${ }^{+}$T-lymphocytes were then cultured at $1.10^{6} / \mathrm{ml}$ with IL-2 $(150 \mathrm{U} / \mathrm{ml})$ and PHA $(1 \mu \mathrm{g} / \mathrm{ml})$ for 3 days and then maintained only with IL-2 for 5 days. Cells were analyzed with a surface staining against hCD4-APC and hCD69-PE (Miltenyi Biotech) or intracellular staining for ADAR and p19 (Zeptometrix) after permeabilization/ 
fixation with the Cytofix/Cytoperm kit (BD). Cells were analyzed on a FACS-Canto II (BD Sciences) collecting 100.000 events. Results were analyzed using the FlowJo software.

\section{Plasmids}

HTLV-1 proviral DNA clone (pACH) was provided by Dr L. Ratner [65]. HTLV-2 proviral DNA clone (pH6neo) and SV2Neo plasmids were provided by Dr P. Green [66]. pSG5M-Tax1, pSG5M-Tax2, HTLV-1- and HTLV-2-LTR-luciferase plasmids were previously described $[15,67]$. ADAR1 wild type and editing-deficient (HAE - > HAG mutation at the position 912) [68] were provided by Dr P. Auewarakul [52]. The 3XF-ADAR1 RNA editing reporter system was provided by Dr. V. Lotteau [40]. PKR wild-type plasmid was provided by Dr E. Meurs [69]. Optineurin wild-type plasmid was previously described [70].

\section{Cell-to-cell infection experiments}

Jurkat $\left(10^{6}\right)$ or PBLs $\left(5.10^{5}\right)$ were transfected with $2.5 \mu \mathrm{g}$ of the HTLV-1 or the HTLV-2-LTR-luciferase plasmids and $2.5 \mu \mathrm{g}$ of the ADAR1 plasmid (Neon ${ }^{\circ}$ Transfection System, Invitrogen) following the manufacturer's instructions. Twenty-four hours later, they were co-cultured with irradiated (77 Gy CIS, BIO international, IBL 637) C91-PL or C19 cells (3:1 ratio). When needed, PBLs were treated with $50 \mu \mathrm{M}$ AZT (Sigma) 24 hours and 3 hours before infection. Twenty-four hours later, reporter activity was assayed (Luciferase reporter assay system, Promega). Luciferase activity was normalized by protein concentration as determined by the Bradford method (Bio-Rad).

$293 \mathrm{~T}\left(3.10^{6}\right)$ cells were seeded onto $100 \mathrm{~mm}$ dishes. Twenty-four hours later, cells were transfected with $4 \mu \mathrm{g}$ of HTLV-1 (pACH) or HTLV-2 (pH6neo) molecular clones and increasing amount $(0,5,50,500 \mathrm{ng})$ of ADAR1 expression plasmid (Polyfect, Qiagen). Forty-height hours posttransfection, 293 T cells were washed and co-cultured with reporter Jurkat-LTR-Luciferase (1:3 ratio) cells for 24 hours. Reporter activities were assayed using the luciferase reporter assay system (Promega) and normalized by protein concentration as determined by the Bradford method (Bio-Rad).

\section{Transfections with HTLV molecular clones}

293T cells $\left(3.10^{6}\right)$ were seeded onto $100 \mathrm{~mm}$ dishes. The following day, $4 \mu \mathrm{g}$ of $\mathrm{pACH}$ (HTLV-1), pH6neo (HTLV-2) or SV2Neo (control) plasmids were transfected with or without 5, 50, $500 \mathrm{ng}$ of ADAR1 using PolyFect reagent (Qiagen) following manufacturer's instructions and cells were treated with increasing amount $(0,10,100,1000 \mathrm{U} / \mathrm{mL})$ of IFN- $\alpha 2$ a (Tebu-Bio) for 48 hours. Reporter activity was assayed (Luciferase reporter assay system, Promega) and normalized by protein concentration as determined by the Bradford method (Bio-Rad).
Jurkat cells $\left(10^{6}\right)$ or PBL $\left(5.10^{5}\right)$ were transfected with $2 \mu \mathrm{g}$ of the HTLV-1 or the HTLV-2-LTR-luciferase plasmids, $2 \mu \mathrm{g}$ of the HTLV-1 (pACH) or HTLV-2 (pH6neo) molecular clones with or without $1 \mu \mathrm{g}$ of the ADAR1 expression plasmid (Neon ${ }^{\circ}$ Transfection System, Invitrogen) following manufacturer's instructions. Forty-eight hours later reporter activity was assayed (Luciferase reporter assay system, Promega). Luciferase activity was normalized by protein concentration as determined by the Bradford method (Bio-Rad).

\section{Fluorescence microscopy}

293T-LTR-GFP cells were seeded at $5.10^{5}$ cells/well on 6well plates. The next day, one microgram of the appropriate plasmid was transfected as described above, with or without the ADAR plasmid. Two days later, cells were visualized and pictures were captured with a Zeiss Axio Vert.A1 imaging microscope.

\section{p19 ${ }^{\text {gag }}$ ELISA}

Cell culture supernatants were collected 48 hours posttransfection and the presence of the HTLV matrix p19 $9^{\text {gag }}$ protein was quantified using a commercially available ELISA kit (Retrotek HTLV-1/2 p19 antigen, Zeptometrix) following the manufacturer's instructions as previously described [11]. In brief, wells are coated with polyclonal antibodies which react with the major gag gene products of HTLV-1 and HTLV-2. Viral antigen in the test specimen is captured by the antibody.

\section{PKR silencing}

$293 \mathrm{~T}$ cells were seeded at a concentration of $3.10^{5}$ cells per well onto 6-well plates. The following day, $20 \mathrm{nM}$ of PKR siRNA (ON-TARGETplus SMART pool EIF2AK2, Fermentas) or control siRNA (ON-TARGETplus Non-targeting Pool, Fermentas) were transfected (HiPerfect reagent, Qiagen) as previously described [11]. Twelve hours posttransfection, $1.2 \mu \mathrm{g}$ of $\mathrm{pACH}$ or $\mathrm{PH} 6$ neo plasmid were transfected together with $20 \mathrm{nM}$ of siRNA and $125 \mathrm{ng}$ of ADAR1 (Attracten reagent, Qiagen) following the manufacturer's instructions. Cells were collected 48 hours later and analyzed.

\section{Tax Ni-NTA immunoprecipitation}

293T cells were seeded in $10-\mathrm{cm}$ dishes and transfected (Polyfect, Qiagen) with a Tax1-His-encoding plasmid $(4 \mu \mathrm{g})$, together with an OPTN- or a PKR-encoding plasmid $(4 \mu \mathrm{g})$. Twenty-four hours later, cells were harvested and lysed in Chris buffer (50 mM Tris, $0.5 \%$ Nonidet P-40, $200 \mathrm{mM} \mathrm{NaCl}, 0.1 \mathrm{mM}$ EDTA, $100 \mathrm{mM} \mathrm{NaF}, 2 \mathrm{mM}$ $\mathrm{Na}_{3} \mathrm{VO}_{4}, 10 \mathrm{mM}$ imidazole) in the presence of protease inhibitors (Complete, Roche Diagnostics) and incubated with $\mathrm{Ni}^{2+}$-NTA (nitrilotriacetic acid) beads (Sigma) at $+4^{\circ} \mathrm{C}$ under agitation. Beads were then washed extensively in 
Chris buffer. Bound proteins were eluted in Laemmli buffer and processed for immunoblot analyses. The following antibodies were used: anti-His (sc-804, Santa Cruz), anti-OPTN (\#100 000, Cayman Chemical), anti-PKR (71/10, [71]).

\section{Immunoblot analyses}

Cells were washed with PBS, lysed $(50 \mathrm{nM}$ Tris- $\mathrm{HCl}$ pH 7.4, $150 \mathrm{nM} \mathrm{NaCl}, 5 \mathrm{mM}$ EDTA, 0.5\% Nonidet-P-40, $0.2 \mathrm{mM}$ Na3VO4, $50 \mathrm{mM} \mathrm{NaF}, 1 \mathrm{mM}$ dithitheitol, $1 \mathrm{mM}$ phenylmethylsulfonyl fluoride) and protease inhibitors (Complete Roche Applied Science) as previously described [67]. Cell debris were pelleted by centrifugation. Protein concentration was determined by the Bradford method (Bio-Rad). Sixty micrograms of proteins were loaded onto 4-12\% NUPAGE gels (NOVEX, Invitrogen), subjected to electrophoresis at $150 \mathrm{~V}$, and transferred onto a PVDF membrane (Immobilon-P, Millipore). Membranes were blocked in a $5 \%$ milk-PBS- $0.05 \%$ Tween 20 solution, then incubated overnight with the primary antibody (antiADAR1 (Abcam ab88574, 1:1000), anti-PKR 71/10 (1:500) [71], anti-phospho PKR (Epitomics \#1120-1, 1:2000), antiTax-1-specific (Tab 172, 1:1000), anti-Tax-2 (GP3738, 1:4000), [17] anti-HTLV-1/2 p24 (Zeptometrix 75/4.21.11, 1:400), anti- $\beta$-actin clone AC74 (Sigma, 1:40000). The next day, membranes were washed and incubated either with anti-rabbit or with anti-mouse horseradish peroxidaseconjugated secondary antibodies and developed using ECL Plus reagent kit (GE Healthcare).

\section{Additional files}

Additional file 1: Figure S1. Testing the editing capacity of ADAR1wt and ADAR1 mutant constructs. 293-T cells were transfected with $150 \mathrm{ng}$ of the 3XF-ADAR1 RNA editing reporter system with (left) 0, 150, 300, 600, $1000 \mathrm{ng}$ of the plasmid coding for ADAR1 wild-type or with (right) 0, 150, $300,600,1000 \mathrm{ng}$ of the plasmid encoding ADAR1 with a mutation in its catalytic site. Forty-eight hours later, luciferase activity was measured and results normalized to renilla expression and calculated as fold change compared to cells non transfected with ADAR1 plasmid arbitrarily set to $100 \%$. Data are the mean \pm standard deviation (SD) from 2 independent experiments. Asterisks indicate statistically significant differences between treated and untreated cells (paired Student $t$ test, ${ }^{*} p<0.05$; NS: non significant).

Additional file 2: Figure S2. Viral particles produced in the presence of an editing-deficient ADAR1 are still infectious. 293-T cells were transfected with $4 \mu \mathrm{g}$ of (A) $\mathrm{ACH}$ or (B) pH6neo molecular clone together with $500 \mathrm{ng}$ of wild type or mutant ADAR1. Forty-eight hours later, cells were washed and co-cultured with Jurkat-LTR-luc cells for 24 hours (ratio 1:3). Luciferase activity was normalized by protein concentration as determined by the Bradford method and calculated as fold change compared to cells non transfected with ADAR1 plasmid arbitrarily set to 100\%. Paired Student $t$ test, NS: not significant.

\section{Competing interests}

The authors declare that they have no competing interests.

\section{Authors' contributions}

$A C, S A, N L K, A B, R S, F F, C J, H D$ performed experiments. AC, SAC, NLK, JPV RM designed the experiments. AC, FLC, CJ, HD, SA, JPV, AG, RM analyzed the data and wrote the manuscript. All authors read and approved the final manuscript.

\section{Acknowledgments}

$R M, A C$ and $A B$ are supported by Ecole Normale Supérieure de Lyon. RM is also supported by a Contrat Hospitalier de Recherche Translationnelle grant from Assistance Publique des Hopitaux de Paris. NLK was supported by the Croucher Foundation.

SAC was supported by InCa (Cancéropole CLARA). We acknowledge the support of ARC and of La Ligue Contre le Cancer (programme équipe labellisée).

We thank Dr L Ratner and Dr P Green for the gift of different plasmids. We thank Dr E Meurs for the generous gift of the PKR plasmid and of the PKR antibody. The figures were produced by Servier Medical Art.

\section{Author details}

'Equipe Oncogenèse Rétrovirale, Lyon, Cedex 07, France. ${ }^{2}$ Equipe labellisée "Ligue Nationale Contre le Cancer", Lyon, Cedex 07, France. ${ }^{3}$ Centre international de recherche en infectiologie, INSERM U1111 - CNRS UMR5308, Lyon, Cedex 07, France. ${ }^{4} E$ cole Normale Supérieure de Lyon, 46 allée d'Italie, 69364 Lyon, Cedex 07, France. ${ }^{5}$ Université Lyon 1, LabEx ECOFECT -

Eco-evolutionary dynamics of infectious diseases, 69364 Lyon, Cedex 07, France. ${ }^{6}$ Equipe virus enveloppés, Lyon, Cedex 07, France. ${ }^{7}$ Biology Department, Master Biosciences, Lyon, Cedex 07, France. ${ }^{8}$ Unité d'épidémiologie et physiopathoglogie des virus oncogènes, Institut Pasteur, Paris 75015, France. ${ }^{9}$ Unité de rétrovirologie moléculaire, Institut Pasteur, Paris 75015, France.

Received: 23 April 2014 Accepted: 16 October 2014

Published online: 12 November 2014

\section{References}

1. Poiesz BJ, Ruscetti FW, Gazdar AF, Bunn PA, Minna JD, Gallo RC: Detection and isolation of type $C$ retrovirus particles from fresh and cultured lymphocytes of a patient with cutaneous T-cell lymphoma. Proc Natl Acad Sci U S A 1980, 77:7415-7419.

2. Yoshida M, Miyoshi I, Hinuma Y: Isolation and characterization of retrovirus from cell lines of human adult T-cell leukemia and its implication in the disease. Proc Natl Acad Sci U S A 1982, 79:2031-2035.

3. Gessain A, Cassar O: Epidemiological aspects and world distribution of HTLV-1 infection. Front Microbiol 2012, 3:388.

4. Takatsuki T: Adult T-cell leukemia in Japan. In Topics in Hematology. Edited by Seno STS, Irino S. Amsterdam: Excerpta Medica; 1977:73-77.

5. Gessain A, Barin F, Vernant JC, Gout O, Maurs L, Calender A, de The G: Antibodies to human T-lymphotropic virus type-I in patients with tropical spastic paraparesis. Lancet 1985, 2:407-410.

6. Osame M, Usuku K, Izumo S, ljichi N, Amitani H, Igata A, Matsumoto M, Tara M: HTLV-I associated myelopathy, a new clinical entity. Lancet 1986, 1:1031-1032.

7. Bartman MT, Kaidarova Z, Hirschkorn D, Sacher RA, Fridey J, Garratty G, Gibble J, Smith JW, Newman B, Yeo AE, Murphy EL: Long-term increases in lymphocytes and platelets in human T-lymphotropic virus type II infection. Blood 2008, 112:3995-4002.

8. Murphy EL, Fridey J, Smith JW, Engstrom J, Sacher RA, Miller K, Gibble J, Stevens J, Thomson R, Hansma D, Kaplan J, Khabbaz R, Nemo G: HTLVassociated myelopathy in a cohort of HTLV-I and HTLV-II-infected blood donors: the REDS investigators. Neurology 1997, 48:315-320.

9. Anupam R, Doueiri R, Green PL: The need to accessorize: molecular roles of HTLV-1 p30 and HTLV-2 p28 accessory proteins in the viral life cycle. Front Microbiol 2013, 4:275.

10. Bertazzoni U, Turci M, Avesani F, Di Gennaro G, Bidoia C, Romanelli MG: Intracellular localization and cellular factors interaction of HTLV-1 and HTLV-2 Tax proteins: similarities and functional differences. Viruses 2011, 3:541-560.

11. Cachat A, Chevalier SA, Alais S, Ko NL, Ratner L, Journo C, Dutartre H, Mahieux R: Alpha interferon restricts human T-Lymphotropic virus type 1 and 2 De Novo infection through PKR activation. J Virol 2013, 87:13386-13396.

12. Cavallari I, Rende F, Bender C, Romanelli MG, D'Agostino DM, Ciminale V: Fine tuning of the temporal expression of HTLV-1 and HTLV-2. Front Microbiol 2013, 4:235. 
13. Feuer G, Green PL: Comparative biology of human T-cell lymphotropic virus type 1 (HTLV-1) and HTLV-2. Oncogene 2005, 24:5996-6004.

14. Higuchi M, Fujji M: Distinct functions of HTLV-1 Tax1 from HTLV-2 Tax2 contribute key roles to viral pathogenesis. Retrovirology 2009, 6:117.

15. Journo C, Bonnet A, Favre-Bonvin A, Turpin J, Vinera J, Cote E, Chevalier SA, Kfoury Y, Bazarbachi A, Pique C, Mahieux R: Human T cell leukemia virus type 2 taxmediated NF-kappaB activation involves a mechanism independent of Tax conjugation to ubiquitin and SUMO. J Virol 2013, 87:1123-1136.

16. Kannian P, Yin H, Doueiri R, Lairmore MD, Fernandez S, Green PL: Distinct transformation tropism exhibited by human $\mathrm{T}$ lymphotropic virus type 1 (HTLV-1) and HTLV-2 is the result of postinfection T cell clonal expansion. J Virol 2012, 86:3757-3766.

17. Meertens L, Chevalier S, Weil R, Gessain A, Mahieux R: A 10-amino acid domain within human T-cell leukemia virus type 1 and type 2 tax protein sequences is responsible for their divergent subcellular distribution. J Biol Chem 2004, 279:43307-43320.

18. Romanelli MG, Diani E, Bergamo E, Casoli C, Ciminale V, Bex F, Bertazzoni U: Highlights on distinctive structural and functional properties of HTLV Tax proteins. Front Microbiol 2013, 4:271.

19. Barbeau B, Mesnard JM: Making sense out of antisense transcription in human T-cell lymphotropic viruses (HTLVs). Viruses 2011, 3:456-468.

20. Zane L, Jeang KT: The importance of ubiquitination and sumoylation on the transforming activity of HTLV Tax-1 and Tax-2. Retrovirology 2012, 9:103.

21. Journo C, Mahieux R: HTLV-1 and innate immunity. Viruses 2011, 3:1374-1394.

22. Samuel CE: ADARs: viruses and innate immunity. Curr Top Microbiol Immunol 2012, 353:163-195.

23. Kim U, Wang Y, Sanford T, Zeng Y, Nishikura K: Molecular cloning of cDNA for double-stranded RNA adenosine deaminase, a candidate enzyme for nuclear RNA editing. Proc Natl Acad Sci U S A 1994, 91:11457-11461.

24. Hogg M, Paro S, Keegan LP, O'Connell MA: RNA editing by mammalian ADARs. Adv Genet 2011, 73:87-120.

25. Bass BL: RNA editing and hypermutation by adenosine deamination. Trends Biochem Sci 1997, 22:157-162.

26. Bass BL: RNA editing by adenosine deaminases that act on RNA. Annu Rev Biochem 2002, 71:817-846.

27. George CX, Samuel CE: Human RNA-specific adenosine deaminase ADAR1 transcripts possess alternative exon 1 structures that initiate from different promoters, one constitutively active and the other interferon inducible. Proc Natl Acad Sci U S A 1999, 96:4621-4626.

28. George CX, Wagner MV, Samuel CE: Expression of interferon-inducible RNA adenosine deaminase ADAR1 during pathogen infection and mouse embryo development involves tissue-selective promoter utilization and alternative splicing. J Biol Chem 2005, 280:15020-15028.

29. Patterson JB, Samuel CE: Expression and regulation by interferon of a doublestranded-RNA-specific adenosine deaminase from human cells: evidence for two forms of the deaminase. Mol Cell Biol 1995, 15:5376-5388.

30. Samuel CE: Adenosine deaminases acting on RNA (ADARs) are both antiviral and proviral. Virology 2011, 411:180-193.

31. Suspene R, Renard M, Henry M, Guetard D, Puyraimond-Zemmour D, Billecocq A, Bouloy M, Tangy F, Vartanian JP, Wain-Hobson S: Inversing the natural hydrogen bonding rule to selectively amplify GC-rich ADARedited RNAs. Nucleic Acids Res 2008, 36:e72.

32. Gelinas JF, Clerzius G, Shaw E, Gatignol A: Enhancement of replication of RNA viruses by ADAR1 via RNA editing and inhibition of RNA-activated protein kinase. J Virol 2011, 85:8460-8466.

33. Taylor DR, Puig M, Darnell ME, Mihalik K, Feinstone SM: New antiviral pathway that mediates hepatitis $\mathrm{C}$ virus replicon interferon sensitivity through ADAR1. J Virol 2005, 79:6291-6298.

34. Zahn RC, Schelp I, Utermohlen O, Von Laer D: A-to-G hypermutation in the genome of lymphocytic choriomeningitis virus. J Virol 2007, 81:457-464

35. Mohamed YM, Bangphoomi N, Yamane D, Suda Y, Kato K, Horimoto T, Akashi H: Physical interaction between bovine viral diarrhea virus nonstructural protein $4 \mathrm{~A}$ and adenosine deaminase acting on RNA (ADAR). Arch Virol 2014, 159:1735-1741.

36. Li Z, Wolff KC, Samuel CE: RNA adenosine deaminase ADAR1 deficiency leads to increased activation of protein kinase PKR and reduced vesicular stomatitis virus growth following interferon treatment. Virology 2010, 396:316-322

37. Nie Y, Hammond GL, Yang JH: Double-stranded RNA deaminase ADAR1 increases host susceptibility to virus infection. J Virol 2007, 81:917-923.
38. Gandy SZ, Linnstaedt SD, Muralidhar S, Cashman KA, Rosenthal LJ, Casey JL: RNA editing of the human herpesvirus 8 kaposin transcript eliminates its transforming activity and is induced during lytic replication. J Virol 2007, 81:13544-13551.

39. lizasa H, Wulff BE, Alla NR, Maragkakis M, Megraw M, Hatzigeorgiou A, Iwakiri D, Takada K, Wiedmer A, Showe L, Lieberman P, Nishikura K: Editing of Epstein-Barr virus-encoded BART6 microRNAs controls their dicer targeting and consequently affects viral latency. J Biol Chem 2010, 285:33358-33370

40. de Chassey B, Aublin-Gex A, Ruggieri A, Meyniel-Schicklin L, Pradezynski F, Davoust N, Chantier T, Tafforeau L, Mangeot PE, Ciancia C, Perrin-Cocon L, Bartenschlager $R$, Andre $P$, Lotteau $V$ : The interactomes of influenza virus NS1 and NS2 proteins identify new host factors and provide insights for ADAR1 playing a supportive role in virus replication. PLOS Pathog 2013, 9:e1003440.

41. Casey JL: RNA editing in hepatitis delta virus. Curr Top Microbiol Immunol 2006, 307:67-89.

42. Casey JL, Bergmann KF, Brown TL, Gerin JL: Structural requirements for RNA editing in hepatitis delta virus: evidence for a uridine-to-cytidine editing mechanism. Proc Natl Acad Sci U S A 1992, 89:7149-7153.

43. Jayan GC, Casey JL: Increased RNA editing and inhibition of hepatitis delta virus replication by high-level expression of ADAR1 and ADAR2. $J$ Virol 2002, 76:3819-3827.

44. Suspene R, Petit V, Puyraimond-Zemmour D, Aynaud MM, Henry M, Guetard D, Rusniok C, Wain-Hobson S, Vartanian JP: Double-stranded RNA adenosine deaminase ADAR-1-induced hypermutated genomes among inactivated seasonal influenza and live attenuated measles virus vaccines. J Virol 2011, 85:2458-2462.

45. Ward SV, George CX, Welch MJ, Liou LY, Hahm B, Lewicki H, De la Torre JC, Samuel CE, Oldstone MB: RNA editing enzyme adenosine deaminase is a restriction factor for controlling measles virus replication that also is required for embryogenesis. Proc Natl Acad Sci U S A 2011, 108:331-336.

46. Cattaneo R, Billeter MA: Mutations and A/I hypermutations in measles virus persistent infections. Curr Top Microbiol Immunol 1992, 176:63-74.

47. Cattaneo R, Schmid A, Eschle D, Baczko K, ter Meulen V, Billeter MA: Biased hypermutation and other genetic changes in defective measles viruses in human brain infections. Cell 1988, 55:255-265.

48. Patterson JB, Cornu TI, Redwine J, Dales S, Lewicki H, Holz A, Thomas D, Billeter MA, Oldstone MB: Evidence that the hypermutated M protein of a subacute sclerosing panencephalitis measles virus actively contributes to the chronic progressive CNS disease. Virology 2001, 291:215-225.

49. Toth AM, Li Z, Cattaneo R, Samuel CE: RNA-specific adenosine deaminase ADAR1 suppresses measles virus-induced apoptosis and activation of protein kinase PKR. J Biol Chem 2009, 284:29350-29356.

50. Clerzius G, Gelinas JF, Daher A, Bonnet M, Meurs EF, Gatignol A: ADAR1 interacts with PKR during human immunodeficiency virus infection of lymphocytes and contributes to viral replication. J Virol 2009, 83:10119-10128.

51. Doria M, Neri F, Gallo A, Farace MG, Michienzi A: Editing of HIV-1 RNA by the double-stranded RNA deaminase ADAR1 stimulates viral infection. Nucleic Acids Res 2009, 37:5848-5858.

52. Phuphuakrat A, Kraiwong R, Boonarkart C, Lauhakirti D, Lee TH, Auewaraku $P$ : Double-stranded RNA adenosine deaminases enhance expression of human immunodeficiency virus type 1 proteins. J Virol 2008, 82:10864-10872

53. Schoggins JW, Wilson SJ, Panis M, Murphy MY, Jones CT, Bieniasz P, Rice CM: A diverse range of gene products are effectors of the type I interferon antiviral response. Nature 2011, 472:481-485.

54. Kannagi M, Hasegawa A, Takamori A, Kinpara S, Utsunomiya A: The roles of acquired and innate immunity in human T-cell leukemia virus type 1mediated diseases. Front Microbiol 2012, 3:323.

55. Oliere S, Douville R, Sze A, Belgnaoui SM, Hiscott J: Modulation of innate immune responses during human T-cell leukemia virus (HTLV-1) pathogenesis. Cytokine Growth Factor Rev 2011, 22:197-210.

56. Suspene R, Henry M, Guillot S, Wain-Hobson S, Vartanian JP: Recovery of APOBEC3-edited human immunodeficiency virus G-> A hypermutants by differential DNA denaturation PCR. J Gen Virol 2005, 86:125-129.

57. Ko NL, Birlouez E, Wain-Hobson S, Mahieux R, Vartanian JP: Hyperediting of human T-cell leukemia virus type 2 and simian T-cell leukemia virus type 3 by the dsRNA adenosine deaminase ADAR-1. J Gen Virol 2012, 93:2646-2651 
58. Wucherpfennig KW, Hollsberg P, Richardson JH, Benjamin D, Hafler DA: Tcell activation by autologous human T-cell leukemia virus type I-infected T-cell clones. Proc Natl Acad Sci U S A 1992, 89:2110-2114.

59. McMillan NA, Chun RF, Siderovski DP, Galabru J, Toone WM, Samuel CE, Mak TW, Hovanessian AG, Jeang KT, Williams BR: HIV-1 Tat directly interacts with the interferon-induced, double-stranded RNA-dependent kinase, PKR. Virology 1995, 213:413-424.

60. Higuchi M, Single FN, Kohler M, Sommer B, Sprengel R, Seeburg PH: RNA editing of AMPA receptor subunit GluR-B: a base-paired intron-exon structure determines position and efficiency. Cell 1993, 75:1361-1370.

61. Laxminarayana D, Khan IU, O'Rourke KS, Giri B: Induction of 150-kDa adenosine deaminase that acts on RNA (ADAR)-1 gene expression in normal T lymphocytes by anti-CD3-epsilon and anti-CD28. Immunology 2007, 122:623-633.

62. Bazarbachi A, Plumelle Y, Carlos Ramos J, Tortevoye P, Otrock Z, Taylor G, Gessain A, Harrington W, Panelatti G, Hermine O: Meta-analysis on the use of zidovudine and interferon-alfa in adult T-cell leukemia/lymphoma showing improved survival in the leukemic subtypes. J Clin Oncol 2010, 28:4177-4183.

63. Delebecque F, Pramberger K, Prevost MC, Brahic M, Tangy F: A chimeric human T-cell lymphotropic virus type 1 with the envelope glycoprotein of Moloney murine leukemia virus is infectious for murine cells. J Virol 2002, 76:7883-7889.

64. Pais-Correia AM, Sachse M, Guadagnini S, Robbiati V, Lasserre R, Gessain A, Gout O, Alcover A, Thoulouze MI: Biofilm-like extracellular viral assemblies mediate HTLV-1 cell-to-cell transmission at virological synapses. Nat Med 2010, 16:83-89.

65. Kimata JT, Wong FH, Wang JJ, Ratner L: Construction and characterization of infectious human T-cell leukemia virus type 1 molecular clones. Virology 1994, 204:656-664

66. Shimotohno K, Takahashi Y, Shimizu N, Gojobori T, Golde DW, Chen IS, Miwa M, Sugimura T: Complete nucleotide sequence of an infectious clone of human T-cell leukemia virus type II: an open reading frame for the protease gene. Proc Natl Acad Sci U S A 1985, 82:3101-3105.

67. Halin M, Douceron E, Clerc I, Journo C, Ko NL, Landry S, Murphy EL, Gessain A, Lemasson I, Mesnard JM, Barbeau B, Mahieux R: Human T-cell leukemia virus type 2 produces a spliced antisense transcript encoding a protein that lacks a classic bZIP domain but still inhibits Tax2-mediated transcription. Blood 2009, 114:2427-2438.

68. Herbert A, Rich A: The role of binding domains for dsRNA and Z-DNA in the in vivo editing of minimal substrates by ADAR1. Proc Natl Acad Sci U S A 2001, 98:12132-12137.

69. Bonnet MC, Daurat C, Ottone C, Meurs EF: The N-terminus of PKR is responsible for the activation of the NF-kappaB signaling pathway by interacting with the IKK complex. Cell Signal 2006, 18:1865-1875.

70. Journo C, Filipe J, About F, Chevalier SA, Brady JN, Afonso PV, Flynn D, Tangy F, Israël A, Vidalain PO, Mahieux R, Weil R: NRP/Optineurin cooperates with TAX1BP1 to potentiate the activation of NF-kappaB by human T-lymphotropic virus type 1 tax protein. PLoS Pathog 2009, 5:e1000521.

71. Laurent AG, Krust B, Galabru J, Svab J, Hovanessian AG: Monoclonal antibodies to an interferon-induced $\mathrm{Mr} 68,000$ protein and their use for the detection of double-stranded RNA-dependent protein kinase in human cells. Proc Natl Acad Sci U S A 1985, 82:4341-4345.

\section{Submit your next manuscript to BioMed Central and take full advantage of:}

- Convenient online submission

- Thorough peer review

- No space constraints or color figure charges

- Immediate publication on acceptance

- Inclusion in PubMed, CAS, Scopus and Google Scholar

- Research which is freely available for redistribution
C Biomed Central 